\title{
DmytroYenygin
}

Crimean University for the Humanities

\section{TEACHING FOREIGN LANGUAGES in the UNIVERSITIES WESTERN EUROPE (MULTILINGUAL ASPECT)}

\begin{abstract}
The article highlights the experience of teaching foreign languages in the universities in multilingual context of the West-European territory. The author determines reasons that increased attention to education and language learning in higher education in multilingual environment. Also the perspectives for improving foreign language training of students in higher education institutions of the European countries are outlined.
\end{abstract}

One of the priorities of Ukrainian national education policy is integration into the European national education andworld educational space that needs improvement of secondary and higher education.Globalization trends put forward the task of preparing young people for life in a multiethnic, multilingual and multi-cultural space, shaping the skills to communicate and work with people of different nationalities, cultures and mentalities.Therefore, the socio-political and economic priorities of the reform cause particular need for modernization of secondary and higher education in Ukraine foreign language teaching system [Andruschenko, 2003, p. 296].Today, the leading idea in education is teaching foreign languages to acquisition of them as means of interpersonal communication in secondary and higher education - ensuring mastery of foreign languages as a means of interpersonal communication in the professional
field.With the changes in defining the goals of foreign language teaching there are changes in the system of teacher training and organization of foreign language education in institutional education. Recently developed new educational standards, new curricula and programs are made to secure modern communicative aim and introduced interactive textbooks and teaching methods. However, the quality of young citizens' knowledge of a foreign language, unfortunately, is not sufficient.

Recently, the issue of foreign language education became the subject of attention of many scientists, including W. Hamanyuk (analysis of foreign language education inGermany), P. Gryshkova (foreign language education in Ukraine), L. Hulpy (development of foreign language educationin secondary schools in Hungary), A. Lazarenko (development of foreign language education in UK universities), 
O. Maksymenko (organization of language teachingin higher education in Western Europe), M.Parkhomchuk (multilingualism as the prospect offoreign language education in primary schools in Germany), M. Tadeev (development of modern schoolforeign language education in the member states of the Council of Europe) and other researchers. Yet a further study of foreign experience is worth in the sphere of investigating teaching and learning of languages in the territory of the European space in terms of strategic European choice of Ukraine - asto make strategic decisions and tactics to determine the quality of language training in schools of different educational levels.

The aim of the article is to highlight current practices of language teaching in higher education in multilingual context of WestEuropean countries.

The study shows that the unification of European countries, the creation of the single market, enlargement and internationalization of the industry, mobility and multilingualism in Europe led to the sharp increase in interest in learning foreign languages as a tool for communication and interaction in the multilingual territory. Modern youth is oriented to living in an open globalized socio-political space, which increases understanding of the importance of learning foreign languages to feel at ease with multilingual environment, justifies growing need for educating young people in the understanding of unity, openness, peace, tolerance, interest in the language and culture of other nations and respect for them. Need for understanding other cultures and languages is defined as one of the urgent problems to solution of which schools are actively asked to join. On the one hand, language is seen as a tool - the ability to transfer ideas and information. On the other hand, it is understood as an important part of intellectual development of person's perception and expression, a component of professional competence as a basis for multilingual rivalry in the job market, because it is a multi-phenomenon that connects people, society and national culture [Williams, 2012, p. 61].

Research indicates that language schools and courses are often based on an instrumental approach to teaching foreign languages to meet the needs of students, while the department of foreign languages at universities and colleges emphasizes the correlation issue (connection between language and culture, cognitive aspects, historical circumstances are necessary to understand other cultures in required depth of cultural knowledge and language competence [Williams, 2012, p. 61].The specificity of learning foreign languages in higher education is that all students actually continue to study foreign languages having done the same at school. Therefore, the leading task of postsecondary higher education, on the one hand, isteaching a foreign language in professional direction, and, on the other hand, - the development and improvement of foreign language competence of students, real increase of their proficiency in a foreign language. According to the European Commission the most common languages that are offered for learning in West-European universities as foreign are 
English, French, German, Spanish. $89 \%$ of students are learning English, 32\% - French, 18\% - German, 8\% - Spanish [Eurostat, 2010]. The situation is similar in the educational institutions of Ukraine. And it should be noted that there is a consistently sharp decrease in the number of students studying German, French and Spanish.

Teaching the course "foreign language" in Europe today is communicative - oriented, based on highlighting the multilingual issues. We face there actively developing distance learning system and use of information - communication technologies. In most EU countries the teaching of other school subjects is supported with a foreign language creating a kind of immersion practice. There is a special network "Euroclic", which includes teachers and other stakeholders in the expansion of the direction of studying other subjects in foreign languages. The network publishes a regular newsletter, its Internet - site offers a bank of materials and opportunities for teachers to communicate. European Commission also maintains a website which purpose is the dissemination and exchange of information in thisfield.

In most European countries foreign languages in the universities are taught as a subject specialization in philology departments for the education degree in a foreign language. The course is usually 4-5 years, the curriculum includes the study of language, literature and cultural features of speakers of a particular language. At least two years studentshave to learn another foreign language and culture of its speakers. The list of languages to learn is somewhat wider than at school and includes, depending on the university and the countryFrench, German, Italian, Portuguese, Dutch, Danish (the most popular in Europe) and other languages. Researchers note that the Spanish students of these branches usually get serious theoretical language training, however practical skills to use a foreign language are not sufficient [Palacios, 2002, p. 165].

Studies show that the subject "Foreign Language" is required not in all West-European universities. In many high schools, where the course isrequired as an obligatory component of the curriculum, it is about teaching and learning English, while it does not provide for any other foreign language. For example, in Spain students learn English either as an obligatory course, or as an optional discipline for getting education degrees in pedagogy (primary education), economic law, engineering, physics, chemistry, pharmaceutics. Studying English for special purposes (ESP) is quite wide in universities of Western Europe, but the researchers suggest that much is to be done in this direction for the effective consideration of the interests and needs of students. However, this applies only to English as any other language is not offered for study as an obligatory course or an optional discipline.

This problem is typical for Ukraine and is the subject of discussion and debate. Although the"Foreign language" is an obligatory course of the curriculum in higher education, the number ofhours for the discipline continuously decreases with increasing particle independent learning of students. However, the history of language teaching proved that learning a foreign language 
is most effective during real contact with the teacher within individualized training or group training sessions. Except philology, foreign languages are usually taught at the faculties that train interpreters. The students of these schools specialize in at leasttwo foreign languages, one of which is their main. According to experts, the curriculum of these faculties is more practically oriented compared to the curriculum that is proposed by the Faculty of Philology.

Efforts of recent years with the introduction of new university courses that would combine language learning with scientific, economic, legal educational courses for a double degree of specialization have been made. However, such efforts so far are not very successful.

In universities there also work language centers. Language centers, or as they are called institutions - offer foreign languages to students of the university, faculty and employees of universities.

Studying the experience of teaching and learning foreign languages in higher education in European countries shows that the differences are primarily related to the length of courses and names of specialties. In England and Wales curriculum for the bachelor's degree lasts 3 years. The same length of training of Denmark. In France, a policy of higher education hastwo cycles. At the end of the first cycle students get a diploma overall for university studies (Diploma of General University Studies). After that, students get 1 more year of study leading to the obtaining of the diploma (the Licence) equivalent to the bachelor's degree. In addition to traditional curricula for the educational level in foreign languages in France, students can learn special language courses, which combine the study of two foreign languages with the economy, tourism, political sciences, law, etc. In Portugal training for specialised degree in linguistics lasts 4 years and completes with the diploma of two languages- English and another foreign language, most often German or French. Students who want to teach foreign languages should then undergo special professional teacher training. In the Netherlands training program lasts 4 years. In Germany, the study alsolasts 4 years and completes with a Master's Degree or passing state exams (Level, equivalent to a bachelor's degree does not exist). The curriculum is divided into"Basic" and "Main" stages. A similar model of training is on in Hungary.

The task of creating a European Higher Education Space increased attention to the problem of foreign language education in the multilingual European context. The practice of its realisation in higher education is recognized as unsatisfactory. The fact that its implementation is mostly linked to the training of linguists cannot provide a solution to urgent needs of students and society in general. European experts and researchers in the field of foreign language education believe that the socio- political and economic factors present demand of the program of measures that could promote a truly multilingual and multicultural Europe, a significant role in which must be played by higher education establishments in terms of improving acquisition of foreign languages by students [Williams, 2012, p. 61].

Such a program must presuppose: 
- Creation of a flexible curriculum in which students would be able to specialize in one or two foreign languages in combination with studying technical, economic or legal expertise. So we are to orient on the development of the introduction of degree diplomas with dual specialization (Foreign Language + Economy/ + Law/ + Medicine / + Politicalscience, etc);

- Emphasizing the practical benefits of owninga foreign languages, identify needs of students and society. There is an urgent need for analysis, identifying strengths and weaknesses existing in training programs to develop measures to improve them. More importance of quality control in training and education is to be provided, since the implementation task to create a common European Higher Education Area requires constant support,supervision of adaptation of educational courses to the needs of the changing;

- Offering foreign language at least as an optional course of study in most educational areas;

- Consideration of the process of lifelong language learning as post-secondary educational institutions (including higher education institutions) have an important role in the system of lifelong learning and offer attractive opportunities in the field of language learning;

- Increasing importance of language learning for special purposes, taking into account the conditions of immediate needs of students;

- Development and promotion of foreign language self-study;

- Development of advanced training materials for different educational levels. It is important to attract new technological resources (Internet network distance learning programs). All higher education institutions must have modern equipped resource centers and centers of individualized learning. Other activities to encourage learning outside the classroom include the round tables and seminars on topics concerning the culture of the people whose language is being studied, books/music presentations, movie displays followed by discussion, the organization of foreign language clubs, lectures, foreign languages fairs and more. Students should be directly involved in such activities. They must be true organizers who assist teachers only;

- Training of teachers ready to change learning environment to introduce newtechnology, changes in the educational process, the theoretical and practical innovations, implement new approaches and methods of learning;

- Competitive multilingual training of foreign language teachers willing to teach at least two foreign languages. On the one hand, for European universities it is traditional, on the other hand - it is a' subjective condition for employment of specialists in the labor market;

- Ensuring teachers exchange programs. There is a particular need to establish close bonds between teachers of foreign languages at various educational levels. Exchange Programs should be based on adequate funding. This activity would benefit from support of international organizations such as the French Alliance, British Council, Goethe Institute and others. It is stressed that concrete action has to be taken by 
the European Union, taking care of: financial support, timetable development, teacher training programs, developing educational resources and more.This activity should be done regularly and consistently, which will provide specific effects. Research projects conducted under the supervision of the European Union, justify thatteachers from different countries should be well informed about European initiatives and projects andbe able to be involved in them and feel as subjects of the process;

- Educational materials should allow students to study other subjects using the manuals in foreign languages;

- it is appropriate to conduct research and pilot projects, the results of which should betaken into account in the formulation of national (in each country) and ethnic policy in this area;

- Any innovations must be clearly considered and funded, the discussion should involve teachers, students, members of the publicity, educators - they all have to receive relevant information [Williams, 2012, p. 61].

Study experience of language teaching in the universities of West-European countries suggests real interest of institutions of Europe and the European Union in problems of foreign education in multilingual context. In higher education, yet there was no fundamental change in the quality of European training in foreign languages. However significant changes are noticeable at introduction of projects with the implementation of educational degrees with dual specialization, diversified opportunities for language learning in educational institutions.
However, there are the problems that hammer linguistic diversity posing threat in connection with prevalence of English as a foreign language in higher education. The solutionof the problem lies in establishing the program of action to make foreign language education truly multilingual. 


\section{References:}

Eurostat, Education statistics, Statistics in Focus 49/2010/http://epp.eurostat.ec.europ a.eu/cache/ITY_OFFPUB/KS-SF- 10-049/EN/KS-SF-10-049-EN.PDF

Hamanyuk A. Theory and practice of foreign language education in Germany in the context of Europeanintegration processes): dis. Dr. ped. sciences: 13.00.01 / VA Hamanyuk. - Kiev, 2013. - 498 p.

Ignacio M. Palacios Foreign Language Teaching in Tertiary Education: A European Perspective// CAUCE, Revista de Filologна у suDidбctica, n" 25, 2002. - pбgs. 165-184.: http://cvc.cervantes.e s/literatura/cauce/pdf /cauce25/cauce25_10.pdf

Language: New Perspectives on Language in Education/ The EUNOM Report /G.Williams. - 2012. - 61 p. http://eunom.uoc.edu.

Reform Strategy for Education in Ukraine: Educational Policy Recommendations / [ed. B. Andruschenko]. K.K. I. C, 2003. - 296 p. 